\title{
SENTIDO MÍSTICO NA OBRA DE BOTTICELLI *
}

Hilário Domingues Neto **

\section{Resumo:}

Este artigo se propõe a analisar as manifestaçōes culturais do Renascimento europeu do século XV, partindo da interpretação da obra pictórica "O Nascimento da Vênus", do pintor florentino Sandro Botticelli (1944-1510). Como eixo metodológico toma o "mito enquanto alegoria" e traça uma perspectiva analítico-teórica das relaçōes ideológicas que permeiam as concepções renascentistas do culto à antigüidade.

\section{Palavras-chave:}

Antigüidade clássica, Renascimento, mito como alegoria, ideologia.

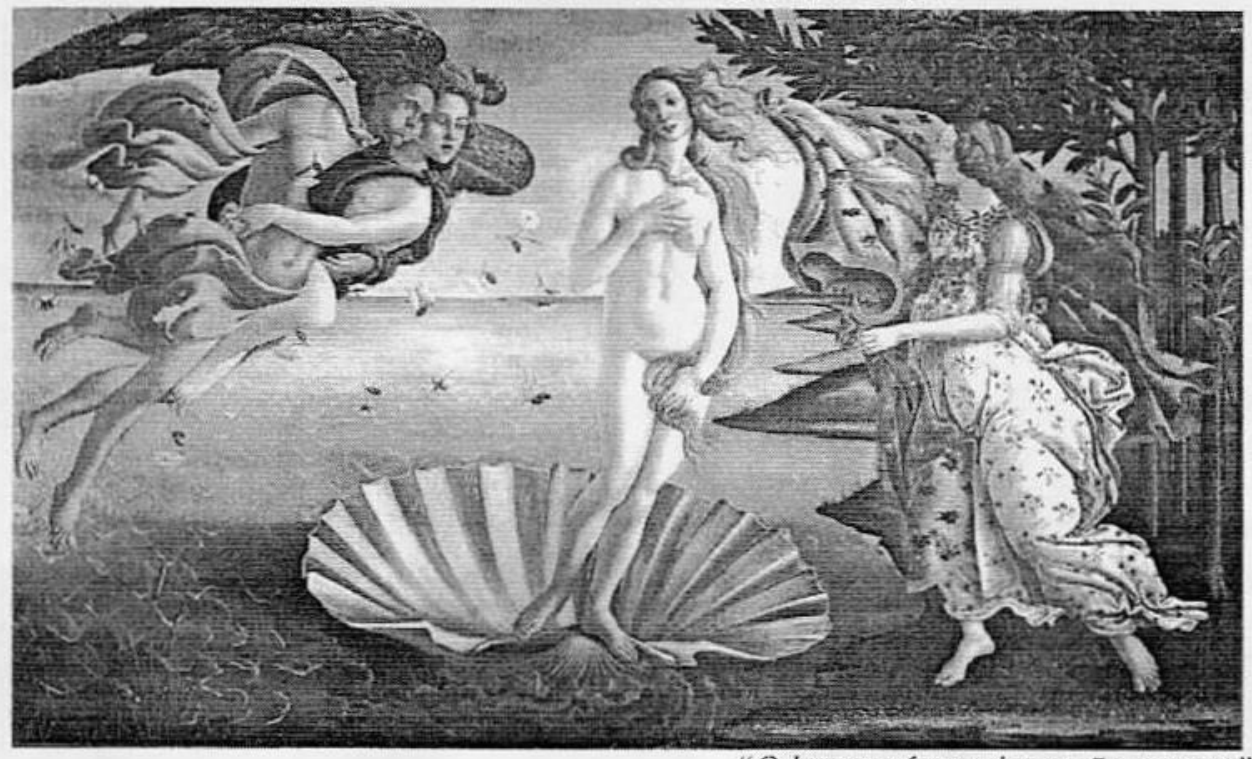

"O homem é uma invençāo recente"

Foucault

\footnotetext{
* Este texto foi originalmente apresentado como trabalho de conclusão da disciplina "Teoria do Mito", do programa de Pós-Graduação em Sociologia da Faculdade de Ciências e Letras da UNESP, sob orientação da Prof". Dr". Silvia Maria Schmuziger de Carvalho.

** Formado em Ciências Sociais pela UNESP. Professor do Departamento de Ciências Humanas e Sociais da UNIARA e também artista plástico.
} 


\section{Introdução}

Este artigo pretende realizar uma abordagem analitica das manifestações culturais do Renascimento na Europa do Quattrocento, onde al visão humanista do mundo apresenta uma proposta restauradora de valores há séculos reprimidos pela instituiçìo clerical feudal.

A reflexäo, centrada na anúlise da obra "O Nascimento de Vênus", concebida em 1484 pelo pintor florentino Sandro Botticelli (1444-1510), nos encaminhará à discussão de algumas categorias possiveis, tais como: a nova concepção nas artes plásticas renascentistas, a burguesia e o mecenato e a interpretação do mito como alegoria.

\section{O momento histórico}

Oadvento da ldade Modema traz em seu bojo transformaços tas mais variadas esferas do conhecimento. À escolástica contrapoe-se o neoplatonismo que busca revigorar o humanismo da Antigüidade Clássica, o qual entraquecido pelo monopólio religioso da Igreja, vai renaseer pela arte no culto mítico do ideal greco-romano.

A ruptura em todos os riveis do conhecimento cientifico determina profundas alteraçōes nos embasamentos éticos e fílosóficos. Ao hado da expansão do comêrcio internacional e urbano, tom lugar uma politica restauradora do poder do Estado apoiada na nova classe detentora do poder econômico, a burguesia.

A censura inquisitóna da igreja medieval, como tantos exemplos históricos de opressaño, sô fez deixar latente, ao coibir a liberdade, a vontade voraz em manifestar o incompativel com a estrutura social emergente. Tais mudanças somente se concretizam quando sustentadas por idéias inovadoras; assim tem sido historicamente, e, no limiar do mundo moderno näo poderia ter sido diferente.

Aos poucos se rompem as amarras repressivas e o discurso na política, na economia, na filosofia, na matemática, na física e nas artes, nas ciências em geral, tenta resgatar o homen da léágica concepfão de mm mundo que circunscrevia a razâa alos desígnios de una fé dogmática.

A burguesia mercantil em seu projeto de ascensäo social passa a ser o agente financiador da cultura, desenvolvendo em seu mecenato o culto a novos padróes de comportamento.

Botticelli foi um dos artistas de grande prestígio no Renascimento e $\mathrm{O}$ Nascimento de Vêmus é considerada a "primeira pintura renascentista com tema exclusivamente leigo mitológico" (Cassis, 1987) e que provavelmente tenha sido executada sob encomenda dos Médicis. Segundo a mitologia antiga, Vênus, a deusa latina do amor, originalmente Afrodite para os gregos, nasceu das espumas do mar, motivo pelo qual tá representaçäo simbólica na obra, de uma ninfa sobre a concha. Referencia-se que Botticelli se inspirara no Hino a Afrodite, de Homero, para a consecuçäo dessa obra.

No entanto, fica a questäo aberta ì análise conclusiva a este trabalho: em que 
sentido o simbolismo presente nessa representaçäo pictónica justifica quaisquer majlicações com o contux to histórico do Renascimento? Esse serí pois o percurso a que nos remeteremos a seguis.

\section{Fundamentaçāo teórica}

Nosso estudo tern a preocupaço de estabeleser um espaço delimitado na pesquisa para dar conta das implicaçęes ideologicas do momento. "Quattrocento" italiano, tomando como objeto de apreciação metodológica a obra do pintor flotentino Sandro Boticelli (1444-1510), que nas artes plasticas fundou grande parte de suas

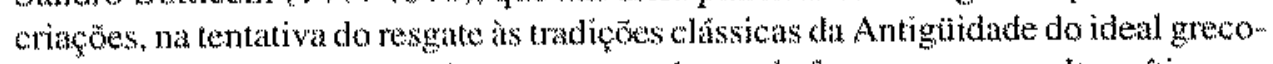
romano, no qual a aça dos deuses se consubstancia fortemente no cutto mítico.

Refomar a Antigiadade significa reler o pensamento daquela epocat, intarpretando-o dentro de uma nova visäo; caso contribio, nada faz sentido; esse foi pois o objetivo da modernidade emergente e se manifestou como já vimos en todos os campos do contrecimento.

Não é objetivo desses artigo discutir o caráter inovador das artes plásticas na ordenaçio do espaço piotórico das composiçoses com o uso da perspectiva. do individualismo antonomia dos produtores de arte, bem como de outras questöes importantes que afloram no momento renascentista $e$ que poderāo nortear fumas proocupaçöes.

Nosso esforço conceitual ante o problema que se nos apresenta requer a análise prévia de certos fenomenos de al gumas categorias.

Num primeiro instante, as implicaçōes filosóficas, sociológicas e histöricas do Renascimento, ou seja, as condiços que remetem o homem moderno a um novo senso perceptivo da realidade, cuja necessidade de expressäo e representaçäo và conduzi+lo a um novo maradgena, tomando por modelo o pensamento clâssico grecom romano.

Qual será pois essa nova ótica? Secundundo tais preocupaços, ama abordagem qu* se pretende conelusiva, sobre a presença na obra em estuóo, de uma iconograta fa mitológica por excelencia, a fim de se processar a uma possivel leitura de seu conteúdo alegórion.

"O Renascimento guis voltar as fontes do pensamento da beleza". (Delumeau, 1984) O homem notalo do munklo de Da Vincie e objeto preocupante dos fijósofos platonicos renascentistas -..... os meoplatonicos como Marcilio Ficino (1433-1499) e Pico della Mirindola (1463-1494) que resgatam o platonismo dentro de uma nova bucia na qual "Platäo ê ofilósofo que mostra a capacidade de o homem elevar-se ao mundo inteligivel e, com 5 so, unir-se a Deus" (Cassis, 1987), a Florença Go centro desse pensamento filosófico na Itaia.

A pintura florentima de Botricelti bem tratuz esse sentimento de intima ligacäo com a natureza universil, do artista que como o deus demiurgo de Platäo reproduz a natureza sobre a tela, mais ainda, produz uma simbiose cntre a natureza contemplada 
* a radidade imaginada alegoricamente.

Num corte sociológico, tomams an Francastel (1982) a seguinte afimativa ".. Toda sociedade que se forma se guia mais ou menos, por um modelo abstrato. Säo os escritores es artistas que exprimem e difundem os traços materiais desse. modelo le mais assiste-se ao encontro, no terreno da arte de homens tab diversos enre si como humides attesás e potentad os a pode-se dizer, en suma, que o grupo de artistas e de sta clientela rem como caracteristica essencial superpor se as chasses e as omas divisous sociais, lembrando antes a figura de m partido ... Fis al simaltancamente a causa a conseguenceia do fato que tendo sempre por materia o real. a arte the acrescenta sempre algo. On prepowe aro homens novas fomulas para a onganiząa dos quadros materiais de sua vida, ou então torna a matśria mais flexível aos descjos do homem, ou remete a soctedade una figufa ideal ou agravada de siomestma."

Sem dúvida as colocaçöes de Francastel endossam mosso pressuposto de que a arte emeryente ma modernidade renascentista, vincula entre si, de um lado uma casse detentora do poder hegemontico, a burguesia, que para se ilustrat vincala-se: de outro, as segmento social produtor de conhecmento, no qual se inserem os artistats.

\section{Leitura do mito enquanto alegoria}

Para estruturamos nossa anilise fundada na categoria "mito enquanto alegoria" recoremos a Furio Jexi, que insert observaçöes sobre o cariter contemporane o da análise ou interprefaça do mito encuanto forma de representaçăo simbolica de um pensamento - alegoria -..." çue em contraposiçäo a visto anturior que a delimina ao "Conjunto de namativas sobte deuses, seres divinos, heróis e viagems (1) alem" (Jesi. 1978), para uma compreensio mas abrangente a tal conceito quando

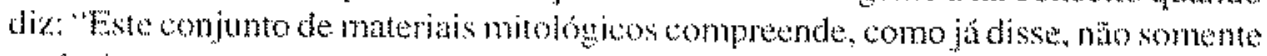

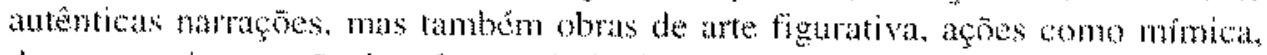
dança etc. A extertsäo da palavra milotogia as obras de arte açoes qua nás entram ma literatura ofal ou escrita, e relativaments moderna (no sentido contemporaneo). fila implica o conhecimeno de umat certa quantidade de material enogrifico sobretudo uma reflexio cientifica que se obrigut a responder a pergunta 'o que é mitologia" que cologue tal pergunta th termos universais ( que é a mitologia como

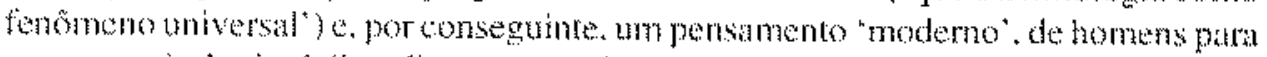
quen a milologite 'imediatamente oferecida pela representaçäo', mas já nöo e imediatanente perceptivel. 'O moderno estudo da mito encontra o seu primeiro obsricuto na diticuldade de circunserever com sulicitnte rigor o seu âmbiro o o sou objeto inclu de fato algumats tautologias ... o mito escapa a qualquer onhecineme cienufico porque é uma espécie de objeto lontusma que, logo que eshá para concretzar. se numa deteminada hipótese. remete implicitamente a cognoscibilidade da stal essencia para uma hipostase precedente hoje inacesivel perdida." (Jesi, 1978).

Assim. para năo inconemos na fat sa consciencia do lenomeno milo, a rabaho 
gue se nos apresenta tem implicaçoes historicas, portanto, năo podemos reduzir a amälise da obra de Botticolli a um mero iconografismo alegórico da mitologia da Antiguidade, mas sim referencis la ao mesno tempo com o contex to do pensamento filosffico em gue esta foi concebida, o do Renascimento.

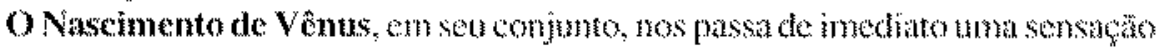
de total equilorio am sua composiçio, como se o atista se realizasse a se aproximat de Deas dommando o todo univeral. Nesse sentido ele extrapola o senso do comm e cria imagens etéreas que nos remetem, quando da contemplą̧ö́, a uma extenuante busca da verdade ali comidis.

Poderamos pattif do pressuposto que a arte foi no Renascimento revitalizada

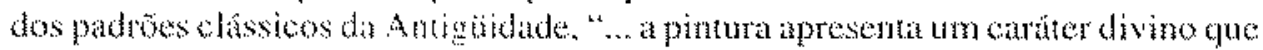
"faz com que o espîtito d. puntu" se transforme numa magem do espirito de beus".

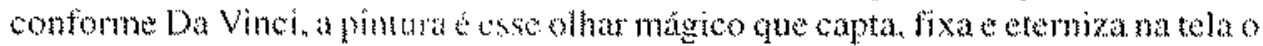
mundo recriado e reordenale flo antista" (Cassis, 1987).

Tomemos como roterto milologico a citaça de Kerenyi (1994) sobre o mito do Nascinento de Afrodite ( Vna ") en sua obra "Os deuses gregos":

"A historia do mascinery de Afrodite, preservada em Hestodo. forma

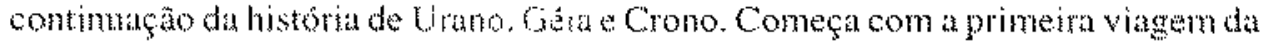
deusa a bha de Chipre, seds des seus mais antigos e poderosos santuarios. os de Pafo e Amato. A história foi desernolvila mum hino que se atribuin a Homero, Mas a contare a historia origimal...

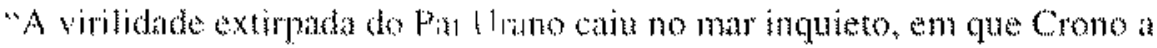
atirara desde a tera fime. Dumants muite tempo ela vagou de um lado para outro. tima espuma branca - aphros - juntou-se. lhe à roda formada da pele imortal. Uma donzela surgive crescen dentro dela. Depos radon primetro para a ilha de Citera e. em seguida para Chipre. Aqui a bela e timida deusa se ergueu da ägu, a uma relva nova comegu a creser the debaix o dos pes. É chamada Afrodite por deuses homens.

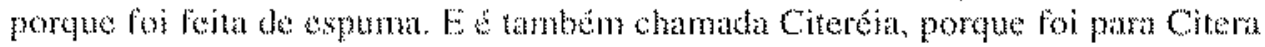
que primeiro nadou...

"O himo homerico conta mais o nodo com que, em Chipre, Afrodite foi recebida e vestida petas Horas. As Horas săo tihas de "Temis, a deusa da lei a da ordem apropriadas às relaçoses naturas dos sexos. A contemplaço da completa nudex da deusa teria sido contrára a Témis - ou tal era a idéfa dos nossos maiores nos tempos antigos, excetuandom os dorm. So depois de vestida engrinaldada adornada. pode Afrodite ser levada para o meío dos deuses. Assim que a viram, fodos a beijaram. agartaram-lhe a mo com tinmeza e procuraram recebe-la por mulher num casamento permanente..." (Kerenyi. 1994).

0 excricio de uma interpretaça alegónca dos elementos temáticos iconograficanente represtentados na obra de Botticelli será tuma pratica no muito simples, requer a prori una análise particularizada de cada integrante do quadro, tentando por fim incoporib-los ao conjunto relacionando-os no que for factivel com 
o contexto mitológico dos hinos homéricos.

Ocorremos anda a necessidade de orientaço guanto ao contexto espacial geográfico do acontecimento. Botticelli ao reatizar sua composiça po pictórica o fez situando a entrada da personagem principal. Afrodite, impusionada de leste para oeste, no Mediterrâneo o gue pernite algumas conexöes entre os elementos em estudo.

A cultura grega, desde seus tempos primitivos apropriou-se do espaço mediterânico en un movimento de contínua expansăo. Para a leste até Gibraltar ...m.". "as colunas de Hércules"---para o sudoeste o Egito no delta do Nilo, para o leste, as costas da Ásia Menor a Chipre na rota costeirn rumo no oriente.

Campoell (1992) haz consideraçós sobre a evoluçāo do mito num reprocessamento cultural dettro do que denomina "zonas mitogenéticas", numa analogia às "zonas de difusầ", nas quais deteminadas representaçes mitologicas se transferem dentro de um processo evolucionista das civilizaçoss. Isso nos permite sustentar que dentro de um processo expansionista implementado por contatos culturais heterogêneos, encontremos na mitologia características análogas a de outros grupos civilizatórios. Assim o método comparativo nos introduzirá em consideráveis sistematizaçoses em nosso trabalho.

Ainda quanto à fonte de inspiração, encontramos no escultor grego Praxíteles. da escola de Atenas, uma centa idemlidade con os padrões que nortearam Botticelli. Assim como a Europa assistu a dertocada do mundo clássico greco romano no fins do século V d.C., o mesmo palco social assistiu nos fins do século IV a.C., ao fim do classicismo helenteo, do qual as gueras do Peloponeso foram um dos fatores determinantes ao tempo que contribuinam para uma signilicativa degeneraça do refinamento cultural grego.

"... Ao longo da disputa [guera do peloponeso] foram-se abrandando os valores que haviam caracterizado o classicismo, e ainda invertendo-se alguns ... esta subversão de valores incidiu nas manifestaços artisticas, não porque tentassem refletir a nowa ordem, mas porque o abandono do chassicismo levava-se a fim num marco onde o propriamente humano começa a reclamar seus direitos. Onde antes haviam nascido deuses, agora eram homens, uns homens idealizados, que ocupavam em sua figura o lugar de deuses, inclusive quando tematicamente se tratava de deuses" (Bozal, 1995).

Nesse contex to humanista, justifica-se ghe o escultor Praxíteles, da escola de Atenas, tenha concebido sua Afrodite de Cnido, que segundo a lenda tivera por musa inspiradora sua amada Frinéu. Tambén Botticelli conforme algumas insinuações literárias teria por modelo para sua concepção de Vênus, a figura feminina de Simonelta Vespacci, amor de Giuliano Médici, que the encomendara a obra.

Comparando a Afrodite de Praxíleles com a Vênus de Bolticelli, realmente constatamos uma identidade marcante na foma expressão. Com uma nudez pudica que propoe o sensual, a Afrodite de Cnido saindo do banho tendo ao lado a jarra de pertumes e manto com o qual irá se envolver, e a Vênus de Botticelli emergindo das águas, em meio ao perfume de rosas e tambén pronta a ser envolvida por uma 
vestimenta trazida por uma Hora. Ainda a coloraçăo marmórea de Vêmus nos induz ao modelo da estátma de Praxíteles (dela não se tem a original, somente reproduçōes, principalmente pelos romanos) em sua concepcăo.

Com relaçăo à nudez de Afrodite e Vênus, a nosso ver, a deusa está transitando do puro para o impuro, do mundo das águas que taz nascer a vida en sua sublime inocencia, para o mundo dos humanos, quando os deuses se materializam em virtudes e imperfefços. Essa transição se faz necessária para estes artistas, que apesar de nāo contemporâneos săo contemplativos de uma ordem social de extrema identidade.

faremos a leitura do quadro da esquerda para a direita, confome sugere Luciano Berti (1978):

Em primeiro plano aparece 7 f́r como entidade fecundadora. Flom, deusa da primavera, abraçada ao seu consorte completa o quadro no qual envoltos num aparente sensualismo parecen querer transmitir a Vênus uma aura de erotisno num anbiente perfumado pelas rosas, enquanto uma elegante ninfa, uma Hora, entidade que personificava uma das estaçōes do ano, no caso a da primavera, encarrega-se de vestir a nudez de Vênuts.

A representação de Vênus sobre uma concha esta ligada à sua concepç̧ăo dos testiculos castrados de Urano e jogados ao mar por seu fillo Cronos, que na uniāo com a espuma branca - aphros - gerou Afrodite.

Sob os pés da Hora uma anêmona floresce, reforçando a idéia da chegada da primavera. A anemona foi a flor gerada do sangue de Adônis, amante de Vênus o morto prematuramente por um javali. Tal representaçăo se refere à intenção da deusa em lembrá-lo a cada ano em que a anemona forescesse. o que acontece de forma efêmera como foi a vida de Adonis.

A primavera é a estação da renovação, assim como o Renascimento o é no contexto social da época, portanto há nesse conteúdo uma forte reciprocidade entre o texto iconográfico e o universo circundante de Botticelli.

Nesse sentido, a forma alegórica com a qual Botticelli estrutura a abra, rellete todo o contexto ideologico que transita da mitologia grega clâssica às preocupaçŏes existenciais do homem do Quatrocento.

\footnotetext{
Anstract:

This article dfers to analysis the cultural manifestations about european Renaissance to the XV century, beginning to the interpretation of pictoric work "the birth of Venus", the flowrence painter Sandto Botticelli (1944-1510). How the methodologyc axle change the "myth as long as allegory" and delineate a perspective theory-analy lics abou ideal relations that penetrate the renaseentists conceptions of the cult by anliguity.
}

Keywords:

Antiquily classic, Renaissance, myth as long as allagory, fleology. 


\section{Referências bibliográficas:}

BERTl, Luciano. História da Arte, Sīo Paulo, Salvat do Brasil, t. 5, 1978.

BOTAL, Valeriano et al. História geral da arte, escultura. Espanha: Ediçoes del Prikdo, v. 1, 1995.

CAMPBELL. Joseph. Máscaras de Deus. São Pato: Palas Athena, 1992.

CASSIS, Céliat, (ed.). História do pensamento: renascinento e lilosofia noderna.

Sino Paulo: Nova Cultural. v.2,1987.

CIVITA, Victor ted. Mestres da pintura: Botticelli. Säo Panlo: Abril Culural. 1977.

CUMMING. Robert. Para entender a arte. Säo Paulo: Álica. 1995.

DELUMEAU. Jem. A Civilizaçāo do Renascimento. Lisboa: Estampa, v.1, 1984. ECO. Humbero. Como se faz uma tese. Sro Pulo: Perspectiva, 1996.

FIKER. Ranl Vico, o precursor. Sāo Paulo: Modema, 1994.

FRANCASTR1. Pierre. A realidade figurativa: elementos estuturais da Sociologia da Arte. Säo Parto: Perspectiva. 1982.

JESI, Furio. O Milo. Säo Pallo: Martits Fontes, 1978.

HATzfELD, Jean. História da Grécia Antiga. Portugal: Publicações EuropaAmérica. 1977.

KERÉNYI. Kart. Os deuses gregos. São Panlo: Cultrix, 1994.

UNIVERSIDADE Estadual de Maringa CADERNOS DE METODOLOOIA E TÉCNICA DE PESQUISA revista anud de metodologia e pesquisa. Maringá. $1,5,1994$ 